\title{
A case of secondary diabetes mellitus associated with chronic arsenic toxicity
}

\author{
John M. Moorman*1,2, Melanie L. Boros ${ }^{1,2}$, Daniela Ciltea ${ }^{3}$, Josephine Taverna ${ }^{4}$, Nairmeen Awad Haller ${ }^{5}$ \\ ${ }^{1}$ Department of Pharmacy, Cleveland Clinic Akron General, Akron, Ohio, USA \\ ${ }^{2}$ Department of Pharmacy Practice, Northeast Ohio Medical University, Rootstown, Ohio, USA \\ ${ }^{3}$ Department of Endocrinology, Diabetes \& Metabolism, Partners Physician Group, Akron, Ohio, USA \\ ${ }^{4}$ Department of Hematology and Oncology, University of Texas Health Center at San Antonio, San Antonio, Texas, USA \\ ${ }^{5}$ Department of Research, Cleveland Clinic Akron General, Akron, Ohio, USA
}

Received: August 15, 2016

DOI: $10.5430 /$ crim.v3n4p55
Accepted: September 20, $2016 \quad$ Online Published: September 29, 2016

URL: http://dx.doi.org/10.5430/crim.v3n4p55

\begin{abstract}
Chronic arsenic exposure leads to systemic illness involving multiple organ systems, and has been associated with the development of diabetes mellitus (DM). While the majority of the literature surrounding arsenic-induced DM is from areas where the arsenic content of drinking water is high, population-based studies in North America have shown a similar association. Here, we present a case of newly-diagnosed DM thought to be secondary to chronic arsenic exposure. The patient was a previously healthy 54-year-old female who presented with progressive fatigue, weight loss and anorexia, and eventually developed colitis, cachexia, skin eruptions, and alopecia. She was also diagnosed with DM, and treatment was complicated by episodes of severe hyper- and hypoglycemia. She was evaluated for autoimmune, rheumatologic, oncologic, and infectious etiologies of her symptoms, all of which were negative. Also negative was an extensive workup for secondary causes of DM. During her final hospitalization, she underwent a workup for heavy metal toxicity, which revealed elevated serum $(11 \mathrm{mcg} / \mathrm{L}$, reference range $<5 \mathrm{mcg} / \mathrm{L})$ and urine $(233.5 \mathrm{mcg} / \mathrm{gram}$ creatinine, reference range $<50 \mathrm{mcg} / \mathrm{gram}$ creatinine) arsenic levels. A diagnosis of arsenic toxicity was made, and the patient underwent chelation therapy with British anti-Lewisite (BAL). This is an interesting case of DM that was thought to be secondary to chronic arsenic exposure. While BAL was effective at lowering arsenic levels, we were unable to observe clinical improvement due to the patient's death shortly after completion of therapy. In cases where other secondary causes of DM are ruled out, it may be prudent to evaluate for heavy metal toxicity to allow for early diagnosis and initiation of treatment. Further studies are needed to determine the efficacy of different treatment strategies for arsenic-induced DM, and whether resolution of arsenic toxicity will reverse the diabetogenic effects.
\end{abstract}

Key Words: Arsenic toxicity, Secondary diabetes mellitus, Chelation therapy, Arsenic-induced diabetes

\section{INTRODUCTION}

Chronic arsenic exposure has been identified as a secondary cause of diabetes mellitus (DM). While the majority of the literature surrounding arsenic-induced DM has involved areas in Taiwan and Bangladesh where the arsenic content of drinking water is high, ${ }^{[1-4]}$ there have been several other population-based studies in North America that have shown a similar association. ${ }^{[5-9]}$ Here, we present a case of newlydiagnosed DM that was thought to be secondary to chronic arsenic exposure.

\footnotetext{
* Correspondence: John M. Moorman; Email: john.moorman@akrongeneral.org; Address: Cleveland Clinic Akron General, Department of Pharmacy, 1 Akron General Avenue, Akron, OH 44307, USA.
} 


\section{CASE REPORT}

A 54-year-old Taiwanese female was admitted to the hospital for the fourth time in five months for progressive fatigue, weight loss and anorexia, along with diarrhea, abdominal pain, and a diffuse skin eruption. Prior to her initial hospital admission, the patient was healthy with no notable medical history. The patient was a homemaker and had no recent travel history or sick contacts. She had no known allergies, family history related to her presenting symptoms, nor history of tobacco, alcohol or illicit drug use. Details of the three preceding hospitalizations are outlined in Table 1.

Table 1. Timeline of hospitalizations

\begin{tabular}{ll}
\hline Hospital Admissions & Hospital Course \\
\hline \multirow{2}{*}{$\begin{array}{l}\text { First admission } \\
\text { (Month 0) }\end{array}$} & Infectious etiologies of colitis ruled out \\
& Colon and rectum biopsies: diffuse active colitis \\
& Renal biopsy: interstitial nephritis and acute tubular necrosis \\
& Prednisone for cutaneous and colitis symptoms, outpatient hemodialysis \\
& New hyperglycemia, hemoglobin A1c = 6.5\% \\
Second admission & Rheumatoid factor, ANA = negative \\
(Month 2) & Skin biopsy: interface dermatitis, hyperkeratosis, pigment incontinence \\
& Abdominal CT: atrophic pancreas, extensive pancolitis \\
& Prednisone and infliximab for colitis, TPN with regular insulin for malnutrition and hyperglycemia \\
& Weakness with shortness of breath shortly after starting infliximab, admission BNP = 1,460 pg/ml \\
& Chest x-ray: bilateral pleural effusions \\
& Abdominal CT: generalized anasarca and moderate ascites \\
& Diffuse rash still present with scaling, new finding of vitiligo \\
Third admission & Developed multiorgan failure requiring intubation and vasopressor therapy, resolved prior to hospital \\
(Month 3) & discharge \\
& Discontinue infliximab due to sepsis, start mesalamine and continue prednisone for colitis, continue TPN \\
& with regular insulin for malnutrition and hyperglycemia \\
& \\
Present admission & \\
(Month 5) &
\end{tabular}

Note. NA: antinuclear antibodies; BNP: brain natriuretic peptide; CT: computed tomography; TPN: total parenteral nutrition.

Table 1 depicts the timeline of hospitalizations from initial presentation (first admission, month 0) up until the final hospitalization in the present report (month 5). Pertinent information from each hospital admission is outlined under Hospital Course.

During her initial hospitalization, it was felt that her skin eruption could have been related to an outpatient course of amoxicillin that she received for a tooth infection, or to chelation therapy that she had started for her symptoms (presumed to contain ethylenediaminetetraacetic acid). She was found to have extensive colitis upon colon and rectal biopsies, and was started on oral steroid therapy for suspected ulcerative colitis. The patient was also found to have acute kidney injury (serum creatinine $=4.9 \mathrm{mg} / \mathrm{dl}$, blood urea nitrogen $=$ $68 \mathrm{mg} / \mathrm{dl}$ ). Renal biopsy revealed interstitial nephritis with acute tubular necrosis, and she was scheduled to receive hemodialysis on an outpatient basis.

Her subsequent hospitalizations were highlighted by worsening colitis, which eventually warranted treatment with infliximab, and continued diffuse skin eruptions which evolved to include depigmentation and alopecia. The patient eventually developed sepsis and multi-organ failure, which required discontinuation of infliximab therapy. Multiple disease processes were investigated to determine the etiology of her progressive symptoms. These included autoimmune, rheumatologic, oncologic, and infectious etiologies, all of which were negative.

Five months after the initial hospitalization, the patient was once again hospitalized for continued weakness, nausea and diarrhea. On physical exam, she was found to be cachectic with diffuse muscle wasting (see Figure 1A), actual body weight was $40 \mathrm{~kg}$ (body mass index, $16.1 \mathrm{~kg} / \mathrm{m}^{2}$ ). There was no pallor, icterus, proptosis, thyromegaly, or edema. Skin examination was significant for non-scarring alopecia (see Figure 1B), generalized maculopapular skin eruption with desquamation on head, trunk and extremities (see Figure 1C), hyperkeratosis of palms and soles of feet, and yellow thickening of her nails with prominent Mee's lines (see Figure 1D). Abdominal examination revealed hyperactive bowel sounds, mild tenderness to deep palpation, but no rebound tenderness 
or guarding. Neurologic examination was notable for absent deep tendon reflexes and hyperesthesia affecting upper and
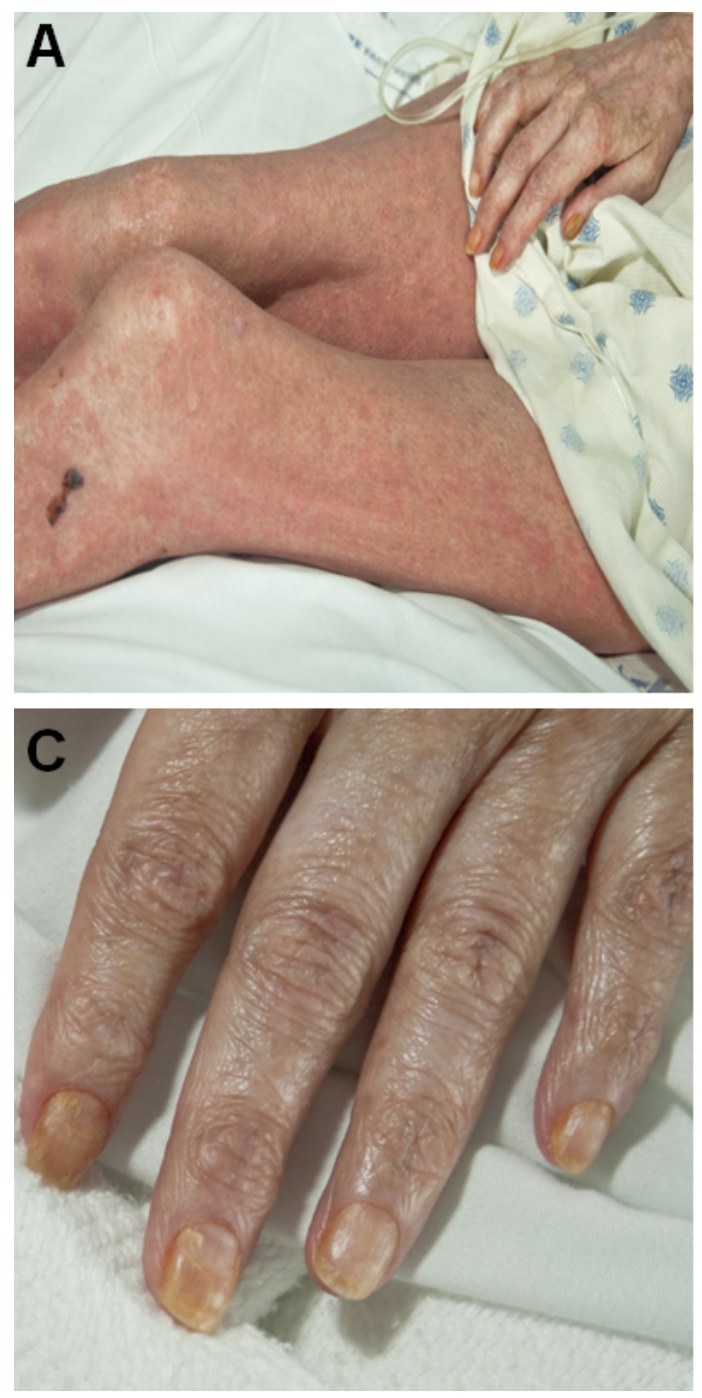

Figure 1. Physical findings of arsenic toxicity

Figure 1 displays the physical findings of arsenic toxicity in the present case. Panel A depicts diffuse muscle wasting. Panel B depicts hypopigmented guttate macules superimposed on hyperpigmentation. Panel C depicts Mee's lines present as white bands traversing the width of the nail. Panel D depicts non-scarring alopecia.

Hyperglycemia developed during her second hospitalization (fasting blood glucose $=483 \mathrm{mg} / \mathrm{dl}$, hemoglobin A1c $=6.5 \%$ ), and the diagnosis of DM was made at that time. Autoimmune causes of DM were ruled out (anti-islet cell and antiglutamic acid decarboxylase antibodies were both negative), and therefore her DM was initially thought to be secondary to corticosteroid administration and the use of continuous tube feeds. Throughout the course of her subsequent hos- lower extremities in a symmetrical pattern. The remainder of the physical examination was unremarkable.
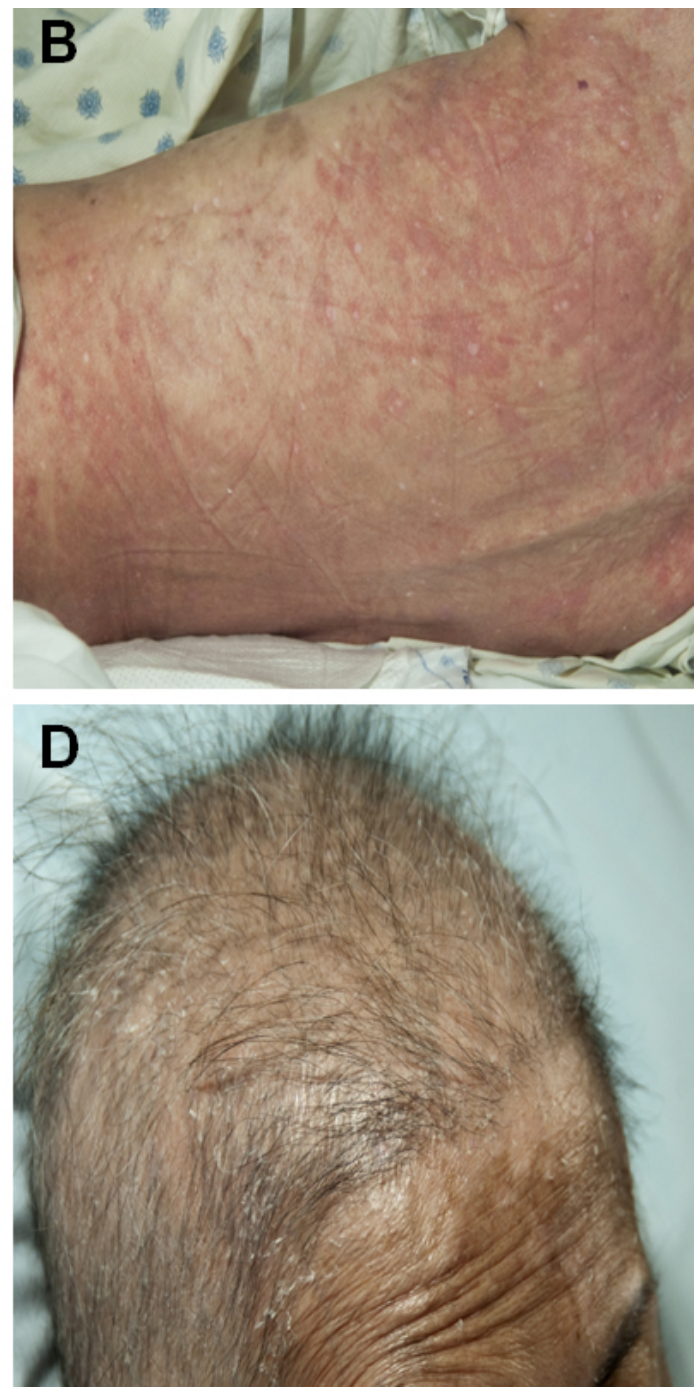

pitalizations, however, treatment was complicated by wide blood glucose fluctuations with severe hypoglycemia despite small subcutaneous insulin doses. As a result, an extensive workup for secondary causes of DM was pursued. Diagnostic evaluation for pancreatitis, pheochromocytoma, acromegaly, glucagonoma, somatostatinoma, and hyperthyroidism were each found to be negative, and an octreotide scan revealed no sign of a neuroendocrine tumor (see Table 2). Of note, she was found to have an undetectably-low C-peptide level $(<0.1 \mathrm{ng} / \mathrm{ml}$, reference range $0.8-3.1 \mathrm{ng} / \mathrm{ml})$ in the setting of hyperglycemia (serum glucose $384 \mathrm{mg} / \mathrm{dl}$, reference range $74-106 \mathrm{mg} / \mathrm{dl})$.

As a result of the patient's complex presentation and her failure to improve despite aggressive supportive care, an in- 
terdisciplinary conference was convened. At that time, heavy metal poisoning was considered as a possible cause of her signs and symptoms. Testing for heavy metals revealed an elevated urine arsenic level of $233.5 \mathrm{mcg} / \mathrm{gram}$ creatinine (reference range $<50 \mathrm{mcg} /$ gram creatinine) and serum arsenic level of $11 \mathrm{mcg} / \mathrm{L}$ (reference range $<5 \mathrm{mcg} / \mathrm{L}$ ). At this point, chronic arsenic toxicity as a secondary cause of DM was considered. Chelation therapy with British anti-lewisite (BAL, dimercaprol) was immediately initiated at $100 \mathrm{mg}$ ( $2.5 \mathrm{mg} / \mathrm{kg}$ body weight) every six hours for two days, then $100 \mathrm{mg}$ every 12 hours for three days, then $100 \mathrm{mg}$ every 24 hours for ten days. Serum arsenic levels were undetectable after five days of starting chelation, and urine levels were undetectable after seven days. For management of her arsenicinduced diabetes, she received insulin therapy throughout her multiple hospitalizations. Glycemic control was extremely labile with prolonged periods of both hyper- and hypoglycemia throughout her hospitalization, but control was somewhat improved following normalization of serum and urine arsenic levels. The patient was transferred to a skilled nursing facility for rehabilitation following BAL therapy, and died shortly thereafter.

\section{Discussion}

Arsenic is a naturally occurring metalloid found commonly in the earth's crust. Organic arsenic compounds, such as those present in seafood, are rapidly eliminated through the urine and pose little health risk, whereas inorganic arsenic (iAs) is considered toxic. ${ }^{[10]}$ While humans may be exposed to iAs through food, dust, and ambient air, the primary source of illness is via consumption of contaminated drinking water or food that is prepared in or irrigated by this water. ${ }^{[11]}$

The term arsenicosis is used to describe the chronic toxicity and resulting illness caused by long-term exposure to arsenic. The manifestations of acute arsenic exposure are generally limited to the gastrointestinal tract, and include severe diarrhea, nausea, vomiting, and abdominal pain. ${ }^{[11]}$ If the source of arsenic is not removed, additional signs and symptoms develop, with specific toxicities depending upon the level and duration of exposure. ${ }^{[12]}$ Dermatological features are generally one of the initial signs of arsenicosis, and often presents as keratosis of the palms and soles, along with a characteristic "raindrop" pattern of hyperpigmentation on the trunk and extremities. ${ }^{[11,12]}$ Arsenicosis has also been associated with the development of peripheral neuropathy, bone marrow suppression, hypertension, cardiovascular disease, and various malignancies, among others. ${ }^{[13-17]}$

In addition to the aforementioned toxicities, arsenicosis is a well-documented secondary cause of DM. Historically, the evidence describing the association with arsenic exposure and prevalence of diabetes came from community-based studies in Taiwan and Bangladesh, where people were exposed to drinking water contaminated with arsenic. ${ }^{[1-4]}$ More recently, evidence from the United States, Mexico and Canada have supported this association, ${ }^{[5-9]}$ and a recent meta-analysis found that every $100 \mathrm{mcg} / \mathrm{L}$ increment of iAs in drinking water was associated with a $13 \%$ increase in the incidence of diabetes. ${ }^{[18]}$ Additionally, there is emerging evidence that arsenic metabolism, as opposed to iAs exposure alone, may play a role in the diabetogenic effects of arsenic. ${ }^{[19]}$

There are several proposed mechanisms for the deleterious effects that arsenic has on glucose regulation, many of which are derived from animal models. Insulin-stimulated glucose uptake, which is thought to be related to interference with GLUT4 translocation and insulin receptor phosphorylation, is one such mechanism. ${ }^{[20,21]}$ Others include inhibition of insulin release, which may be related to both direct beta cell damage and reduced expression of insulin mRNA, as well as alterations in peripheral insulin sensitivity as a result of decreased expression of peroxisome proliferator-activated receptor gamma (PPAR $\gamma) .{ }^{[2-24]}$ Conversely, arsenic has been shown in animal models to inhibit insulin-induced glucose transport and gluconeogenesis, which may lead to hypoglycemia. ${ }^{[25-27]}$ This evidence was supported by a recent cohort study, which indicated that the metabolic changes associated with arsenic-induced diabetes have very little overlap with those associated with type 1 and type 2 diabetes. ${ }^{[28]}$

Although these theorized mechanisms may help to guide how treatment of arsenic-induced DM is approached, the first steps in treating arsenic toxicity are to provide supportive care and to identify and remove the source of exposure. In patients with suspected arsenic exposure who present with severe illness, chelation therapy should be started as soon as possible (i.e., prior to laboratory confirmation), as treatment within 6 hours of exposure has shown to improve survival and encephalopathy in animal models. ${ }^{[29]}$ In those who present without clear signs or symptoms, the decision to initiate chelation therapy may be postponed until arsenic exposure is confirmed via hair or urine samples.

In the United States, there are currently only two chelation agents available for treatment of arsenic toxicity; BAL and 2,3-dimercaptosuccinic acid (DMSA, succimer). Although there are no human trials evaluating the safety and efficacy of BAL in patients exposed to arsenic, it may be used via an intramuscular injection for acute toxicity and dosed based on the clinical severity. ${ }^{[30]}$ However, in addition to injection site pain, BAL is associated with a high rate of dose-dependent adverse reactions, which may include nausea, vomiting, headache, and hypertension. ${ }^{[29,31-33]}$ 
Moreover, there is a concern that BAL administration results in redistribution of arsenic into the brain and testes, as demonstrated in animal models. ${ }^{[34-36]}$

DMSA was developed as a more hydrophilic analog of BAL, and therefore is associated with fewer adverse reactions. ${ }^{[37]}$ In animal models, DMSA was associated with improved survival and similar arsenic elimination rates as compared to BAL. ${ }^{[35,36,38]}$ However, its efficacy for treatment of arsenic toxicity is limited to case reports and animal experiments; the only prospective trial using DMSA in humans, which was conducted in a small group of people in West Bengal exposed to arsenic-contaminated drinking water, showed no additional clinical improvement when compared to placebo. ${ }^{[39]}$ Additionally, animal models suggest that DMSA may be inferior to BAL in critically-intoxicated patients or those with chronic exposure (who will likely have a higher concentration of intracellular arsenic) due to the relatively high membrane permeability of BAL. ${ }^{[36,38]}$

The present case provides an excellent example of the clinical progression of arsenicosis. Following her initial presenting symptoms of nausea and diarrhea (which are common initial symptoms of arsenic toxicity), her clinical course eventually included many of the known features of chronic exposure, including hyperkeratosis of the palms and soles, hyperpigmentation of the trunk and extremities, peripheral neuropathy, and hyperglycemia. We began chelation therapy shortly after confirmation of arsenic toxicity via serum and urine levels, although there was a short lag between identifying the toxicity and obtaining the BAL. The decision to use BAL over DMSA in this patient was based largely upon the patient's clinical presentation. Given the fact that multiple organ systems were involved in the presented case, we felt that it was likely that she had been exposed to arsenic chronically over the course of her hospitalizations. As previously discussed, the evidence suggests that BAL has a higher membrane permeability compared to DMSA, and may therefore have better efficacy in patients with chronic exposure. ${ }^{[36,38]}$ Indeed, the patient's serum and urine arsenic levels dropped below the threshold for detection by the completion of her course of therapy. Additionally, the dose of BAL that was used (2.5 $\mathrm{mg} / \mathrm{kg}$ ) was within the recommended range of $2.5-3 \mathrm{mg} / \mathrm{kg}$, above which dose-dependent adverse effects become more frequent.

Table 2. Results from evaluation for causes of diabetes mellitus

\begin{tabular}{|c|c|c|c|}
\hline Cause & Test(s) Performed & Test Result & Reference Range \\
\hline Acromegaly & Serum IGF-1 & $<25 \mathrm{ng} / \mathrm{ml}$ & $92-190 \mathrm{ng} / \mathrm{ml}$ \\
\hline \multirow{3}{*}{ Autoimmune } & Anti-GAD antibodies & $<1 \mathrm{unit} / \mathrm{ml}$ & $1 \mathrm{unit} / \mathrm{mL}$ or less \\
\hline & Anti-islet cell antibodies & Negative & Negative \\
\hline & Serum C-peptide & $0.1 \mathrm{ng} / \mathrm{ml} *$ & $0.8-3.1 \mathrm{ng} / \mathrm{ml}$ \\
\hline Glucagonoma & Serum glucagon & $<50 \mathrm{pg} / \mathrm{ml}^{*}$ & $60 \mathrm{pg} / \mathrm{ml}$ or less \\
\hline \multirow{4}{*}{ Hyperthyroidism } & TSH & 5.08 units/L & 0.34-4.82 units/L \\
\hline & Free thyroxine & $1.15 \mathrm{ng} / \mathrm{dl}$ & $0.89-1.76 \mathrm{ng} / \mathrm{dl}$ \\
\hline & Anti-TPO antibodies & 29.6 & $0-60$ \\
\hline & Anti-thyroglobulin antibodies & 45.3 units $/ \mathrm{ml}$ & 0-60 units/ml \\
\hline \multirow{3}{*}{ Pancreatitis } & Serum amylase & 21 units/L & 25-115 units/L \\
\hline & Serum lipase & 162 units/L & 114-286 units/L \\
\hline & Abdominal CT & No evidence of acute pancreatitis & N/A \\
\hline \multirow{7}{*}{ Pheochromocytoma } & Fractionated plasma catecholamines: & & \\
\hline & Epinephrine & $26 \mathrm{pg} / \mathrm{ml}$ & $<95 \mathrm{pg} / \mathrm{ml}$ \\
\hline & Norepinephrine & 386 pg/ml & $217-1,109 \mathrm{pg} / \mathrm{ml}$ \\
\hline & Dopamine & $<30 \mathrm{pg} / \mathrm{ml}$ & $<30 \mathrm{pg} / \mathrm{ml}$ \\
\hline & Fractionated serum metanephrines: & & \\
\hline & Metanephrine & $<25 \mathrm{pg} / \mathrm{ml}$ & $<57 \mathrm{pg} / \mathrm{ml}$ \\
\hline & Normetanephrine & $<74 \mathrm{pg} / \mathrm{ml}$ & $<148 \mathrm{pg} / \mathrm{ml}$ \\
\hline \multirow[b]{2}{*}{ Somatostatinoma } & Serum somatostatin & $23 \mathrm{pg} / \mathrm{ml}$ & $10-22 \mathrm{pg} / \mathrm{ml}$ \\
\hline & Octreotide scan & $\begin{array}{l}\text { No evidence to suggest a somatostatin } \\
\text { receptor positive tumor }\end{array}$ & N/A \\
\hline
\end{tabular}

Note. CT: computerized tomography; GAD: glutamic acid decarboxylase; IGF-1: insulin-like growth factor-1; TPO: thyroid peroxidase; TSH: thyroid stimulating hormone. * Serum glucose at the time of testing was $384 \mathrm{mg} / \mathrm{dl}$. 
Table 2 depicts the results from the evaluation of potential causes of diabetes mellitus for the present case. For each potential cause, the biochemical test(s) that were performed are listed herein. While the suppressed C-peptide in the presence of hyperglycemia suggests beta cell dysfunction, each of the listed causes of diabetes mellitus were ruled out as shown.

Many of the alternative etiologies for the patient's signs and symptoms were ruled out throughout the course of her care, providing further substantiation that her course of illness was indeed related to arsenic toxicity. Similarly, we feel that it was highly probable that the patient's DM was secondary to arsenic exposure. Although the initial etiology was thought to be related to steroid therapy, this is typically associated with increases in insulin resistance. However, in the present case, her average daily insulin requirement was approximately 17 units ( 0.4 units/kg/day), indicating that she retained insulin sensitivity. Given the absence of diabetes-related autoantibodies, we felt that it was prudent to pursue an evaluation for other secondary causes of DM, which is depicted in Table 2. Pancreatitis, which may lead to beta cell dysfunction, was ruled out based on biochemical and radiographic evaluation. Somatostatinoma, which may present with a triad of diabetes, cholelithiasis and diarrhea, and glucagonoma, which may present with a migratory rash, were ruled out on the basis of biochemistry and negative octreotide scan. As mentioned previously, Other disorders known to cause DM, including hyperthyroidism, pheochromocytoma and acromegaly, were ruled out on a biochemical basis as well. By ruling these etiologies out, we have more reason to believe that arsenic toxicity at least played a role in the development of this patient's DM. Many of the aforementioned theories surrounding arsenic-induced DM involve either inhibition of insulin release or direct beta cell damage, as well as inhibition of gluconeogenesis. These theories are supported in the present case, given the undetectably low Cpeptide level in the setting of hyperglycemia, as well as the frequent hypoglycemic episodes which were seen throughout her course of therapy.

While this case provides an excellent example of the clinical implications of arsenic exposure, there are some limitations to consider. The fact that we did not discover the source of the patient's arsenic exposure raises some important issues, the first of which is that removing the source of arsenic would have been critical to the patient's recovery. Secondly, we could not determine the type of arsenic that the patient was exposed to (i.e., organic vs. inorganic). As previously discussed, organic arsenic is commonly found in shellfish and seafood and generally does not pose a health risk, whereas iAs is considered toxic. ${ }^{[10]}$ Neither the patient's occupation nor residence would have raised suspicion of arsenic expo- sure through drinking water or inhalation, and the patient denied any recent travel to areas where environmental exposure is known to be high nor any acute change in seafood intake. We did discover that the patient had been ingesting seaweed tea, which has been shown to contain various amounts of iAs, depending on the source and type. ${ }^{[40]}$ However, we did not suspect arsenic toxicity as the cause of her presentation until late into the course of her care, and were unable to obtain samples this product for testing prior to the patient's death. Finally, although we did have confirmation that the patient was exposed to arsenic from blood and urine samples, we were unable to obtain adequate hair or nail samples to confirm chronic exposure. However, given the progressive decline of the patient's health over the course of several months, as well as the clinical signs and symptoms that the patient exhibited, suspicion of chronic (as opposed to acute) arsenic exposure remained high.

To our knowledge, there are no studies that have evaluated treatment strategies for arsenic-induced DM, nor are there observations of whether pancreatic function returns to baseline after arsenicosis is resolved. We felt that insulin therapy was most appropriate in this patient, and that oral antihyperglycemic agents would have predisposed her to adverse effects in the hospital setting given her poor oral intake, gastrointestinal symptoms and frequent hypoglycemic episodes. As mentioned within the case presentation, we noticed wide fluctuations in glycemic control despite the use of small doses of subcutaneous insulin (see Figure 2). Once BAL therapy was initiated and urine arsenic levels became undetectable, we did notice a decrease in the variability of her daily average blood sugars (see Figure 3), but the withinday fluctuations remained significant (data not shown). In addition, the variability in day-to-day insulin requirements had noticeably decreased towards the end of her final hospitalization, which may have been associated with decreased arsenic burden. Unfortunately, the patient died shortly after completion of chelation therapy and normalization of urine and serum arsenic levels, and we were therefore unable to observe the clinical course of DM after treatment of her arsenicosis.

Figure 2 shows the average daily insulin (black triangles) and prednisone (gray bars) in conjunction with average daily blood glucose readings (black squares) for each hospital day. As depicted early in the hospital stay, small adjustments in daily insulin doses often resulted in large changes in daily average glucose readings. After chelation therapy was initiated (day 19) and urine arsenic levels normalized (day 25), the fluctuation in daily insulin dose and average daily blood glucose decreased substantially. 


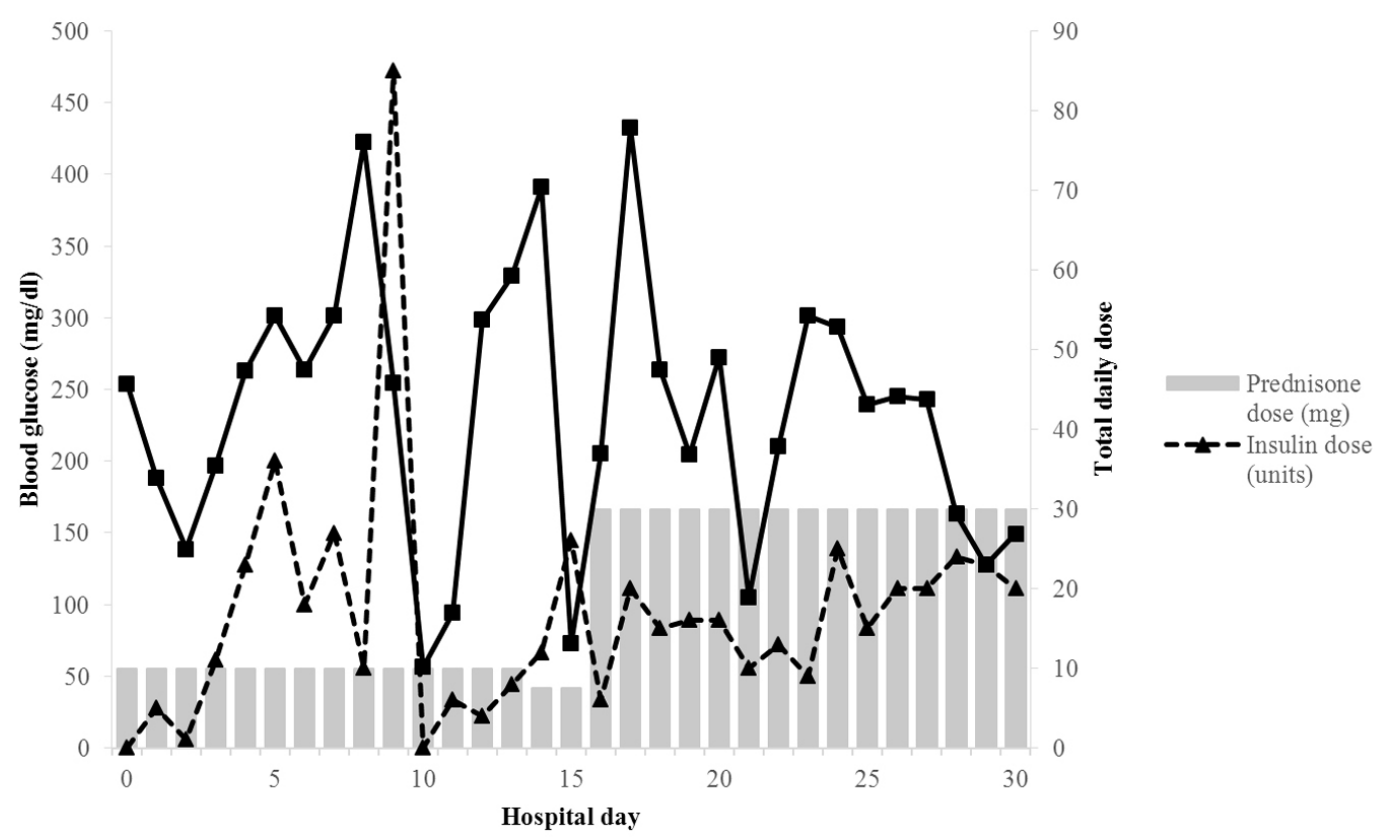

Figure 2. Summary of total daily insulin and prednisone doses and associated average daily blood glucose readings

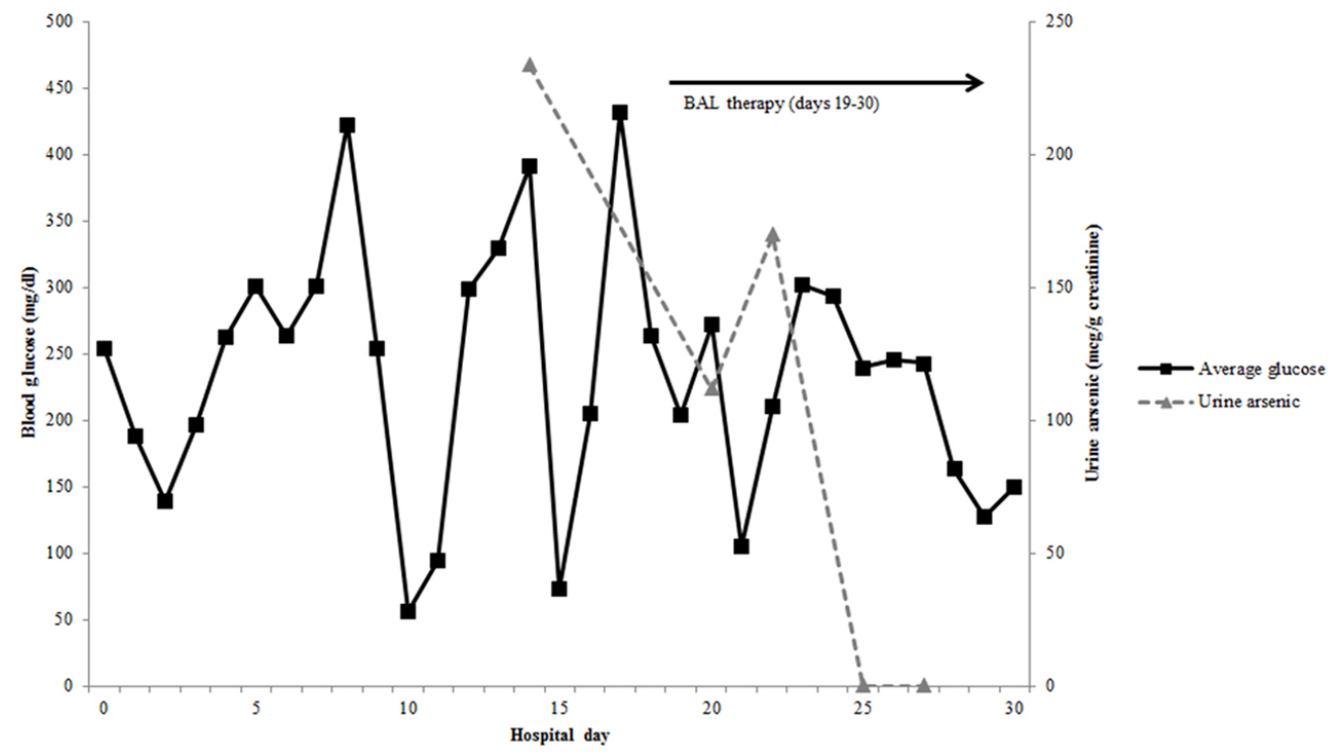

Figure 3. Summary of average daily blood glucose before and during chelation therapy

Figure 3 shows the average daily blood glucose readings (black squares) for each hospital day along with daily urine arsenic levels (gray triangles). The arrow in the top-right of the figure shows the timeline of chelation therapy with British anti-Lewisite (BAL) in conjunction with normalization of urine arsenic levels, and thereafter a decrease in the fluctuation of daily average blood glucose.

In conclusion, we presented a case of newly-diagnosed DM that was thought to be secondary to chronic arsenic exposure where other causes of DM were ruled out. This case supports the use of BAL for normalization of urine and serum Published by Sciedu Press arsenic levels in suspected chronic arsenic toxicity, although we were unable to determine whether clinical improvement would have ensued. In cases where other secondary causes of DM are ruled out, it may be prudent to evaluate for heavy metal toxicity to allow for early diagnosis and initiation of treatment. Further studies are needed to determine the efficacy of different treatment strategies for arsenic-induced $\mathrm{DM}$, and whether resolution of arsenicosis will reverse the diabetogenic effects.

\section{CONFLicts of InTEREST Disclosure}

The authors have declared no conflicts of interest. 


\section{REFERENCES}

[1] Lai MS, Hsueh YM, Chen CJ, et al. Ingested inorganic arsenic and prevalence of diabetes mellitus. American Journal of Epidemiology. 1994; 139(5): 484-492. PMid:8154472

[2] Tseng CH, Tai TY, Chong CK, et al. Long-term arsenic exposure and incidence of non-insulin-dependent diabetes mellitus: a cohort study in arseniasis-hyperendemic villages in Taiwan. Environmental Health Perspectives. 2000; 108(9): 847-851. PMid:11017889 http://dx.doi.org/10.1289/ehp.00108847

[3] Rahman M, Tondel M, Ahmad SA, et al. Diabetes mellitus associated with arsenic exposure in Bangladesh. American Journal of Epidemiology. 1998; 148(2): 198-203. PMid:9676702 http: //dx.doi.org/10.1093/oxfordjournals.aje.a009624

[4] Rahman M, Tondel M, Chowdhury IA, et al. Relations between exposure to arsenic, skin lesions, and glucosuria. Occupational and Environmental Medicine. 1999; 56(4): 277-281. PMid:10450246 http://dx.doi.org/10.1136/oem.56.4.277

[5] Gribble MO, Howard BV, Umans JG, et al. Arsenic exposure, diabetes prevalence, and diabetes control in the Strong Heart Study. American Journal of Epidemiology. 2012; 176(10): 865-874. http: //dx.doi.org/10.1093/aje/kws153

[6] James KA, Marshall JA, Hokanson JE, et al. A case-cohort study examining lifetime exposure to inorganic arsenic in drinking water and diabetes mellitus. Environmental Research. 2013; 123: 33-38. http://dx.doi.org/10.1016/j.envres. 2013.02.005

[7] Kim NH, Mason CC, Nelson RG, et al. Arsenic exposure and incidence of type 2 diabetes in Southwestern American Indians. American Journal of Epidemiology. 2013; 177(9): 962-969. http: //dx.doi.org/10.1093/aje/kws329

[8] Del Razo LM, Garcia-Vargas GG, Valenzuela OL, et al. Exposure to arsenic in drinking water is associated with increased prevalence of diabetes: a cross-sectional study in the Zimapan and Lagunera regions in Mexico. Environmental Health. 2011; 10: 73 http://dx.doi.org/10.1186/1476-069X-10-73

[9] Feseke SK, St-Laurent J, Anassour-Sidi E, et al. Arsenic exposure and type 2 diabetes: results from the 2007-2009 Canadian Health Measures Survey. Health Promotion and Chronic Disease Prevention in Canada. 2015; 35(4): 63-72. PMid:26083521

[10] Gomez-Caminero A, Howe P, Hughes M, et al. Environmental Health Criteria 224: Arsenic and arsenic compounds. Geneva, Switzerland: World Health Organization, International Programme on Chemical Safety. 2001. Available from: http://apps.who.int/iris/bi tstream/10665/42366/1/WHO_EHC_224.pdf

[11] World Health Organization. Exposure to Arsenic: A Major Public Health Concern. Geneva, Switzerland: World Health Organization. 2010. Available from: http://www.who.int/ipcs/features/ arsenic.pdf

[12] Guha Mazumder DN. Chronic arsenic toxicity \& human health. The Indian Journal of Medical Research. 2008; 128(4): 436-447. PMid:19106439

[13] Mukherjee SC, Rahman MM, Chowdhury UK, et al. Neuropathy in arsenic toxicity from groundwater arsenic contamination in West Bengal, India. Journal of Environmental Science and Health. Part A, Toxic/Hazardous Substances \& Environmental Engineering. 2003; 38(1): 165-183. http://dx.doi.org/10.1081/ESE-120 016887

[14] Terada H, Sasagawa T, Saito H, et al. Chronic arsenical poisoning and hematopoietic organs. Acta Medica et Biologica. 1962; 9: 279-292.

[15] Chen CJ, Hsueh YM, Lai MS, et al. Increased prevalence of hypertension and long-term arsenic exposure. Hypertension. 1995; 25(1): 53-60. PMid:7843753 http://dx.doi.org/10.1161/01. HYP. 25.1.53
[16] Chen CJ, Chiou HY, Chiang MH, et al. Dose-response relationship between ischemic heart disease mortality and long-term arsenic exposure. Arteriosclerosis, Thrombosis and Vascular Biology. 1996; 16(4): 504-510. http://dx.doi.org/10.1161/01.ATV.16.4.504

[17] International Agency for Research on Cancer. Monographs on the evaluation of carcinogenic risks to humans: Arsenic and arsenic compounds (Group 1). Geneva, Switzerland: World Health Organization, International Agency for Research on Cancer. 1987. Available from: http://monographs.iarc.fr/ENG/Monograph s/vol100C/mono100C-6.pdf

[18] Wang W, Xie Z, Lin Y, et al. Association of inorganic arsenic exposure with type 2 diabetes mellitus: a meta-analysis. Journal of Epidemiology and Community Health. 2014; 68(2): 176-184. http://dx.doi.org/10.1136/jech-2013-203114

[19] Kuo CC, Howard BV, Umans JG, et al. Arsenic exposure, arsenic metabolism, and incident diabetes in the Strong Heart Study. Diabetes Care. 2015; 38(4): 620-627. http://dx.doi.org/10. 2337 /dc14-1641

[20] Paul DS, Harmon AW, Devesa V, et al. Molecular mechanisms of the diabetogenic effects of arsenic: inhibition of insulin signaling by arsenite and methylarsonous acid. Environmental Health Perspectives. 2007; 115(5): 734-742. PMid:17520061 http://dx.doi.org/10. 1289/ehp. 9867

[21] Walton FS, Harmon AW, Paul DS, et al. Inhibition of insulindependent glucose uptake by trivalent arsenicals: possible mechanism of arsenic-induced diabetes. Toxicology and Applied Pharmacology. 2004; 198(3): 424-433. PMid:15276423 http://dx.doi.org/10. 1016/j . taap. 2003.10.026

[22] Boquist L, Boquist S, Ericsson I. Structural beta-cell changes and transient hyperglycemia in mice treated with compounds inducing inhibited citric acid cycle enzyme activity. Diabetes. 1988; 37(1): 89-98. PMid:3275558 http://dx.doi.org/10.2337/diab.37.1.89

[23] Diaz-Villasenor A, Sanchez-Soto MC, Cebrian ME, et al. Sodium arsenite impairs insulin secretion and transcription in pancreatic $\beta$-cells. Toxicology and Applied Pharmacology. 2006; 214(1): 3034. PMid:16413591 http://dx.doi.org/10.1016/j.taap. 20 05.11 .015

[24] Wauson EM, Langan AS, Vorce RL. Sodium arsenite inhibits and reverses expression of adipogenic and fat cell-specific genes during in vitro adipogenesis. Toxicological Sciences. 2002; 65(2): 211219. PMid:11812925 http://dx.doi.org/10.1093/toxsci/65 .2 .211

[25] Reichl FX, Kreppel H, Szinicz L, et al. Effect of glucose treatment on carbohydrate content in various organs in mice after acute As2O3 poisoning. Veterinary and Human Toxicology. 1991; 33(3): 230-235. PMid: 1858302

[26] Reichl FX, Szinicz L, Kreppel H, et al. Effect of arsenic on carbohydrate metabolism after single or repeated injection in guinea pigs. Archives of Toxicology. 1988; 62(6): 473-475. PMid:3250379 http://dx.doi.org/10.1007/BF00288353

[27] Szinicz L, Forth W. Effect of As2O3 on gluconeogenesis. Archives of Toxicology. 1988; 61(6): 444-449. PMid:3190442 http://dx.d oi.org/10.1007/BF00293690

[28] Martin E, Gonzalez-Horta C, Rager J, et al. Metabolomic characteristics of arsenic-associated diabetes in a prospective cohort in Chihuahua, Mexico. Toxicological Sciences. 2015; 144(2): 338-346. http://dx.doi.org/10.1093/toxsci/kfu318

[29] Eagle H, Magnuson HJ. The systematic treatment of 227 cases of arsenic poisoning (encephalitis, dermatitis, blood dyscrasias, jaundice, fever) with 2,3-demercaptopropanol (BAL). American Journal of Syphilis, Gonorrhea, and Venereal Diseases. 1946; 30(5): 420-441. PMid:21000085 
[30] Akorn Inc. BAL in Oil: dimercaprol injection USP. 2008. Available from: http://http://www. akorn.com/documents/catalog/ package_inserts/17478-526-03.pdf

[31] Longcope WT, Luetscher JA, Wintrobe MM, et al. Clinical uses of 2,3-dimercaptopropanol (BAL); the treatment of arsenical dermatitis with preparations of BAL. The Journal of Clinical Investigation. 1946; 25(4): 528-533. http://dx.doi.org/10.1172/JCI101734

[32] Mahieu P, Buchet JP, Roels HA, et al. The metabolism of arsenic in humans acutely intoxicated by As2O3: its significance for the duration of BAL therapy. Clinical Toxicology. 1981; 18(9): 1067-1075. PMid:7318390 http://dx.doi.org/10.3109/1556365810899 0336

[33] Carleton AB, Peters RA, Stocken LA, et al. Clinical uses of 2,3dimercaptopropanol (BAL); the treatment of complications of arsenotherapy with BAL (British anti-lewisite). The Journal of Clinical Investigation. 1946; 25(4): 497-527. PMid:21001625 http: //dx.doi.org/10.1172/JCI101733

[34] Kosnett MJ. The role of chelation in the treatment of arsenic and mercury poisoning. Journal of Medical Toxicology. 2013; 9(4): 347-354. http://dx.doi.org/10.1007/s13181-013-0344-5

[35] Aposhian HV, Carter DE, Hoover TD, et al. DMSA, DMPS, and DMPA - as arsenic antidotes. Fundamental and Applied Toxicol- ogy. 1984; 4(2 Pt 2): S58-S70. http://dx.doi.org/10.1016/0 272-0590 (84) 90138-6

[36] Kreppel H, Reichl FX, Szinicz L, et al. Efficacy of various dithiol compounds in acute As2O3 poisoning in mice. Archives of Toxicology. 1990; 64(5): 387-392. PMid:2169719 http://dx.doi.org/1 $0.1007 /$ BF01973461

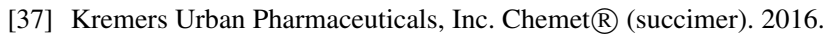
Available from: http://recordatirarediseases.com/wp-c ontent/uploads/2015/11/Chemet-PI .pdf

[38] Muckter H, Liebl B, Reichl FX, et al. Are we ready to replace dimercaprol (BAL) as an arsenic antidote? Human \& Experimental Toxicology. 1997; 16(8): 460-465. http://dx.doi.org/10.1177/0 96032719701600807

[39] Guha Mazumder DN, Ghosal UC, Saha J, et al. Randomized placebocontrolled trial 2,3-dimercaptosuccinic acid in therapy of chronic arsenicosis due to drinking arsenic-contaminated subsoil water. Journal of Toxicology. Clinical Toxicology. 1998; 36(7): 683-690. PMid:9865236 http://dx.doi.org/10.3109/1556365980916 2616

[40] Rose M, Lewis J, Langford N, et al. Arsenic in seaweed-forms, concentration and dietary exposure. Food and Chemical Toxicology. 2007; 45(7): 1263-1267. PMid:17336439 http://dx.doi.org/1 $0.1016 / j$. fct .2007 .01 .007 